\title{
Answers to the Quiz: Carotid artery ultrasound on page...
}

1.On Figures 1 and 2 (See quiz on page ...) we can see mainly type 2 plaque (predominantly echolucent lesions having less than $50 \%$ echogenic components) at the posterior wall of the left internal carotid artery (ICA).

According to the Geroulakos classification (1) plaques are classified into 5 types:

Type 1 completely echolucent lesions, sometimes a thin fibrous cap is visible;

Type 2 predominantly echolucent lesions having less than $50 \%$ echogenic components;

Type 3 predominately echogenic with less than $50 \%$ echolucent components;

Type 4 uniformly dense echogenic lesions (with less than $10 \%$ echolucent components);
Type 5 plaques that could not be accurately classified due to excessive plaque calcification and acoustic shadowing.

Characterization of carotid plaques is important as it allows us to choose the correct approach to patient treatment. According to G. Geroulakos et al. (1) type 1 and 2 plaques are unstable and tend to embolize.

2. According to AIUM guidelines "Ultrasound Examination of the Extracranial Cerebrovascular System" (2) each vascular laboratory might have their own interpretation criteria that are derived from the literature or from internal validation. We are going to use a grading system that is based on worldwide accepted consensus (3), represented in Table 1.

Table 1. Carotid artery stenosis: gray-scale and Doppler ultrasound criteria

\begin{tabular}{|c|c|c|c|c|}
\hline \multirow[b]{2}{*}{$\begin{array}{l}\text { Degree of } \\
\text { Stenosis (\%) }\end{array}$} & \multicolumn{2}{|c|}{ Primary Parameters } & \multicolumn{2}{|c|}{ Additional Parameters } \\
\hline & $\begin{array}{l}\text { ICA PSV } \\
(\mathrm{cm} / \mathrm{sec})\end{array}$ & $\begin{array}{c}\text { Plaque Estimate } \\
(\%)^{\star}\end{array}$ & $\begin{array}{c}\text { ICA/CCA PSV } \\
\text { Ratio }\end{array}$ & $\begin{array}{l}\text { ICA EDV } \\
(\mathrm{cm} / \mathrm{sec})\end{array}$ \\
\hline Normal & $<125$ & None & $<2.0$ & $<40$ \\
\hline$<50$ & $<125$ & $<50$ & $<2.0$ & $<40$ \\
\hline $50-69$ & $125-230$ & $\geq 50$ & $2.0-4.0$ & $40-100$ \\
\hline $\begin{array}{c}\geq 70 \text { but less than } \\
\text { near occlusion }\end{array}$ & $>230$ & $\geq 50$ & $>4.0$ & $>100$ \\
\hline Near occlusion & $\begin{array}{l}\text { High, low, or } \\
\text { undetectable }\end{array}$ & Visible & Variable & Variable \\
\hline Total occlusion & Undetectable & $\begin{array}{l}\text { Visible, no } \\
\text { detectable } \\
\text { lumen }\end{array}$ & Not applicable & Not applicable \\
\hline
\end{tabular}

CCA - Common carotid artery, EDV - end diastolic velocity, ICA - Internal carotid artery, PSV - peak systolic velocity (Reproduced from ref . 3 - Grant EG, Benson CB, Moneta GL, Alexandrov AV, Baker JD, Bluth El. Carotid artery stenosis: gray-scale and Doppler US diagnosis--Society of Radiologists in Ultrasound Consensus Conference. Radiology 2003; 229: 340-6. Copyright 2003, with permission of RSNA)

Address for Correspondence: Ihor Hayda, Danylo Halytsky Lviv National Medical University, Lviv, Ukraine, Email: ihayda@gmail.com

Received: 16.04.2020 Revised: 13.05.2020 Accepted: 14.05.2020 
In this case, as we can see from Figures 2 and 4 (See Quiz on page..), peak systolic velocity (PSV) of the left ICA is $131 \mathrm{~cm} / \mathrm{s}$ and end-diastolic velocity (EDV) of the left ICA is $43 \mathrm{~cm} / \mathrm{s}$. The main criterion is the velocity of blood flow and based on the systolic and end-diastolic velocity criteria itself we could report that this patient has $50-69 \%$ degree of stenosis of the left ICA. However, ICA/common carotid artery (CCA) PSV ratio is less than 2.0. It is very important to make sure that we do not overestimate the degree of stenosis, especially since we discovered potentially unstable type 2 carotid plaque and many vascular surgeons might use this result to decide whether this patient would need a surgical intervention. Numerous factors may falsely increase or decrease velocities (e.g. systemic disease, cardiovascular disease, etc.) (4). Therefore, if there is any doubt, secondary criteria such as ratios may be helpful in these circumstances. Thus, we measured the degree of stenosis in crosssectional plane and the degree of stenosis in this case was $66 \%$ based on the area reduction. Take into consideration that the area reduction and diameter reduction are not equal (Fig. 1) (5). Then we can estimate that the degree of stenosis is less than $50 \%$.

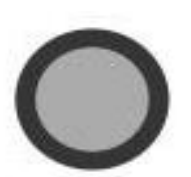

\%Area

\%Diameter

\begin{abstract}
$44 \%$
\end{abstract}
$25 \%$

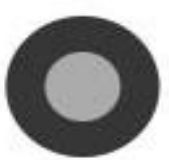

$75 \%$

$50 \%$

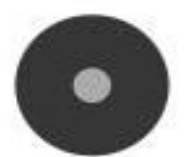

$94 \%$

$75 \%$

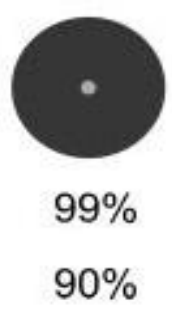

Figure 1. The relationship between area reduction and diameter reduction

(Modified from ref .5 - Ota H, Takase K, Rikimaru H, Tsuboi M, Yamada T, Sato A, et. al. Quantitative vascular measurements in arterial occlusive disease. RadioGraphics 2005: 25: 1141-58. Copyright 2005, with permission of RSNA)

What do we have in this case? On one hand, findings suggestive of more than $50 \%$ stenosis: high PSV and EDV values, the presence of aliasing at the stenosis site and spectral broadening. On the other hand, the other findings suggestive of lower than $50 \%$ stenosis: a low ICA/CCA PSV ratio, area stenosis value of $66 \%$, which corresponds to less than $50 \%$ in diameter, flow reversal at the stenosis site.

According to Danziger et al. (6), Doppler ultrasound is the least accurate in diagnosing moderate degrees of stenosis (50-69\%), often overestimating the degree of stenosis in this category.

Taking to consideration additional imaging in cross sectional area, this patient most likely has less than $50 \%$ stenosis of the left ICA. Based on the additional parameters, such as ICA/CCA PSV ratio, we were able to suspect the possibility of overestimation of the degree of stenosis. The take-home message is: "Using the "peak systolic velocity" as the sole criterion has some serious limitations"(7). Clinicians need to be aware of the limitations of duplex ultrasound scanning when making management decisions.

3. The correct answer is aliasing (Fig. 2 ). Aliasing arises when the Doppler shift of the moving blood is higher than half of the PRF (Nyquist limit). Aliased signals are displayed with the wrong direction (red instead of blue and vice versa) and velocity (the hue of the color). An aliasing artifact is usually associated with the increased flow velocity in the stenotic segment. 


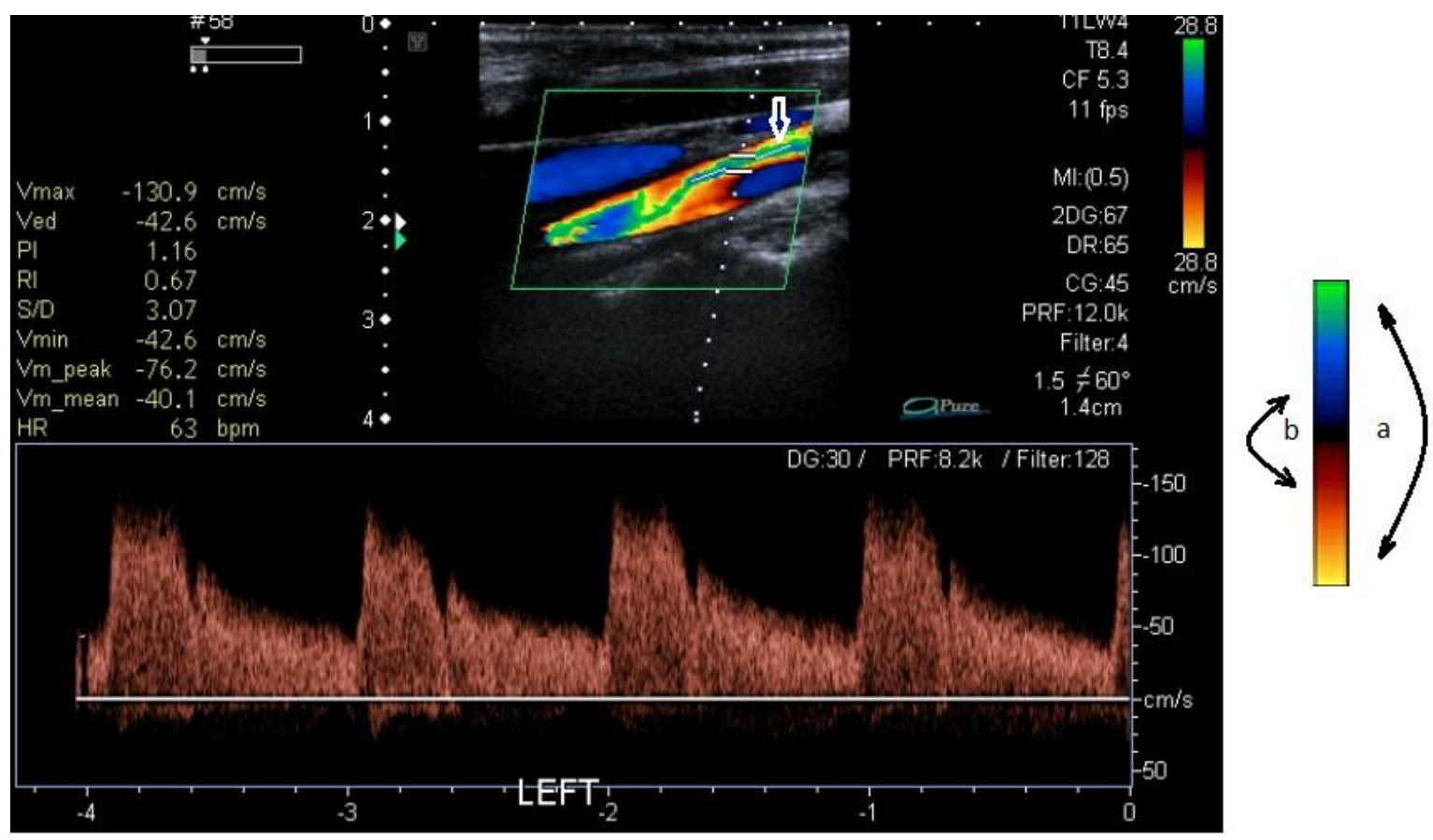

Figure 2. Color coding with the aliasing effect. The aliasing effect, shown here with a white arrow is characterized by a transition of the orange and yellow shades at one end of the color scale to light blue and green shades at the other end of the scale (a)

4. The correct answer is flow reversal (Fig. 3). The visual difference between the transient blood flow reversal in the posterolateral aspect of the carotid bulb and aliasing is the color of the boundary layer, which separates flows. That layer is always black in case of flow reversal and white if it is aliasing. Why is it so important to recognize the presence or absence of the flow reversal on the level of the carotid bulb?
When atherosclerosis develops, it preferentially involves the posterolateral bulb region, obliterating the normal configuration of the sinus with consequent loss of the flow separation zone. It was therefore hypothesized that if flow separation could be detected, it should be predictive of a normal angiogram (8).

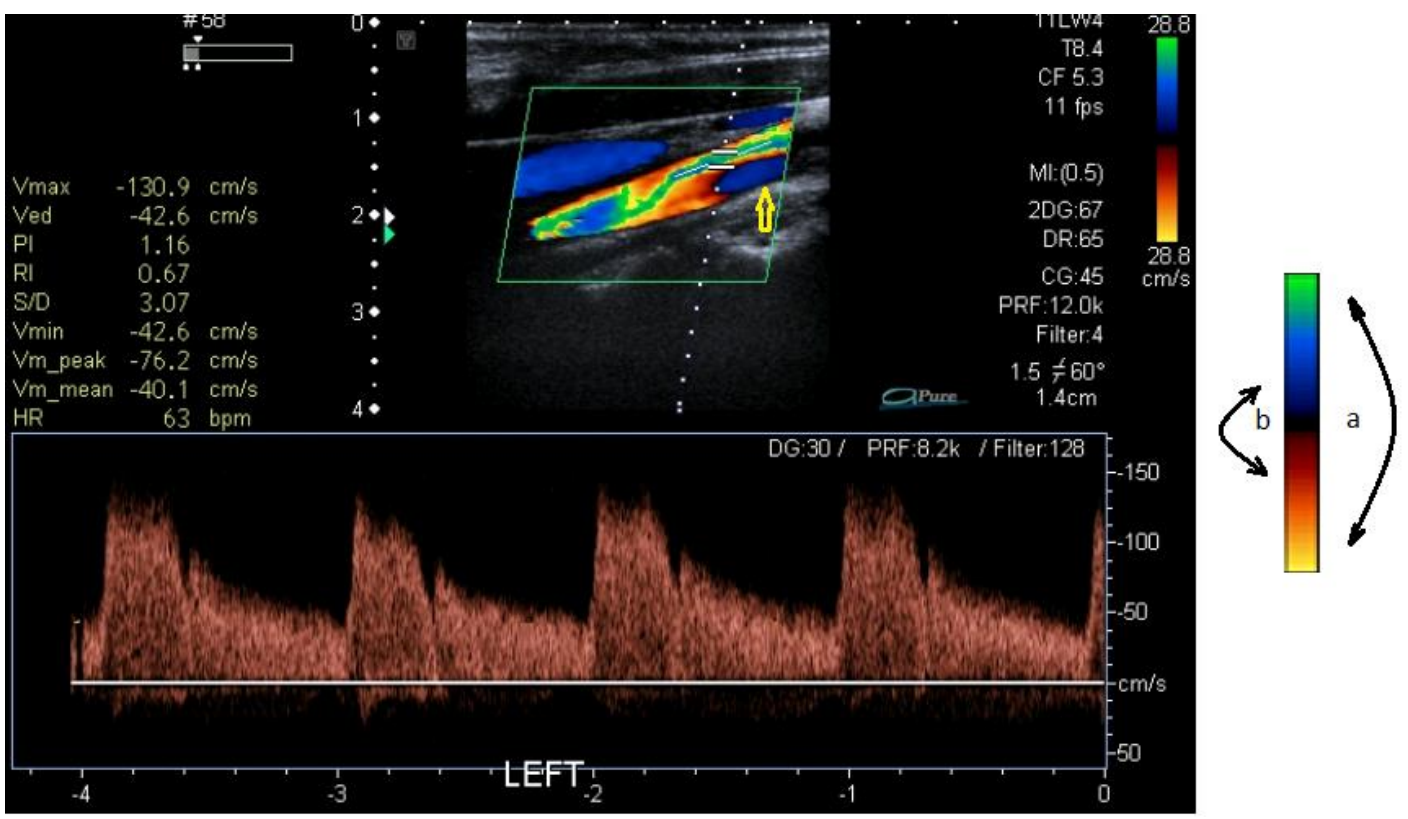

Figure 3. Color coding in the case of a true change in flow direction and comparison of true change in flow direction versus aliasing. Folding over or wrapping around of the color as a result of change in flow direction (yellow arrow). The transition of red to dark blue (b) proceeds through a black line, which represents a velocity of $0 \mathrm{~cm} / \mathrm{s}$ 


\section{The correct answer is spectral broadening.}

Widening of the spectral line and filling of the spectral window is called spectral broadening. Spectral broadening is normally seen in the presence of high flow velocity, at the branching of a vessel, or in smalldiameter vessels.

Ihor Hayda, Mykhaylo Sorokivskyy, Ihor Volodymyr Hayda

Danylo Halytsky Lviv National Medical University, Lviv, Ukraine

Peer-review: internal and external

Conflict of interest: None to declare

Authorship: I.H., M.S., and I.V.H. have equally contributed to preparation of quiz

Acknowledgement and funding: None to declare

\section{References:}

1.Geroulakos G, Ramaswami G, Nicolaides A, James K, Labropoulos N, Belcaro $\mathrm{G}$, et al. Characterization of symptomatic and asymptomatic carotid plaques using high-resolution real-time ultrasonography. Br J Surg 1993; 80: 1274-7. doi/pdf/10.1161/01.STR.20.2.175

2. AIUM practice guideline for the performance of an ultrasound examination of the extracranial cerebrovascular system. J Ultrasound Med 2012; 1: 145-54.
3.Grant EG, Benson CB, Moneta GL, Alexandrov AV, Baker JD, Bluth El. Carotid artery stenosis: gray-scale and Doppler US diagnosis--Society of Radiologists in Ultrasound Consensus Conference. Radiology 2003; 229: 340-6. doi:10.1148/radiol.2292030516.

4.Grant EG, Duerinckx AJ, El Saden SM, Melany ML, Hathout GM, Zimmerman PT. Ability to use duplex US to quantify internal carotid arterial stenoses: fact or fiction? Radiology 2000; 214: 247-52.

5.Ota H, Takase K, Rikimaru H, Tsuboi M, Yamada T, Sato $A$, et. al. Quantitative vascular measurements in arterial occlusive disease. RadioGraphics 2005: 25: 1141-58.

6. Danziger A, Velayudhan V, Pawha P. What is the accuracy of ultrasound imaging for stenosis in stroke? 2018. Available at: URL: https://emedicine.medscape.com/article/338385overview\#a4

7. von Reutern GM, Goertler MW, Bornstein NM, Del Sette M, Evans DH, Hetzel A, et al. Grading carotid stenosis using ultrasonic methods. Stroke 2012; 43: 916-21.

8.Nicholls SC, Phillips DJ, Primozich JF, Lawrence LR, Kohler TR, Rudd TG, et al. Diagnostic significance of flow separation in the carotid bulb. Stroke 1989; 20: 175-82. 